\title{
How to conserve biological diversity: Perspectives from Ambio
}

\author{
This article belongs to Ambio's 50th Anniversary Collection. Theme: Biodiversity \\ Conservation
}

\author{
Jeffrey A. McNeely
}

Published online: 10 February 2021

Biological diversity (biodiversity for short) provides a powerful example of how a new term can generate substantial international action. The utility of treating genes, species, and ecosystems together emerged in the mid-1980s, highlighted by an international convergence of university researchers, economists, foresters, agroecologists, ethicists, and government resource managers brought together by the visionary Edward O. Wilson (Wilson 1988), perhaps inspired by his earlier work on sociobiology (Wilson 1975). This broad constituency addressed both the threats to biodiversity and the social, scientific, and economic benefits of its conservation. The next step was a series of discussions organized by the United Nations Environment Program (UNEP) among governments and non-governmental conservation organizations about how to promote more effective international cooperation to address the problem of biodiversity loss. The climax of this effort was agreement on a Convention on Biological Diversity (CBD 1992) at the Rio de Janeiro Earth Summit on 5 June, entered into force on 29 December 1993 (Sayer et al. 2021), and has now been ratified by all but one of the UN member countries (ironically, the only non-party is the USA, which played an active role in its negotiation and is deeply affected by its provisions).

One of the innovations of the CBD was the attention given to traditional ecological knowledge (article $8 \mathrm{j}$ ), a topic that has been well addressed in Ambio. Shortly after the CBD was agreed, Gadgil et al. (1993) provided detailed examples of the resource management practices of people who have long depended on their local ecosystems for their survival and cultural identity, often supported by their belief systems that give spiritual values to key resource systems such as watershed protection forests. The principles of indigenous rights to resources and the value of traditional knowledge are now in the mainstream of biodiversity conservation, and community-based resource management systems are enhancing the land rights of indigenous peoples in many parts of the world (Doyle 2015; Gilbert 2016). Gadgil et al. (2021) have brought this concept up to date, showing that traditional knowledge is still relevant to the modern challenges to conserving biodiversity.

The CBD's Strategic Plan for Biodiversity 2011-2020 was highly relevant to protected areas as a major conservation tool (Pimm 2021; Sayer et al. 2021). Its target 11 called for establishing at least $17 \%$ of terrestrial and inland water biomes as protected areas, along with $10 \%$ of coastal and marine biomes. These were to be effectively and equitably managed, ecologically representative, and well connected as parts of systems of effective area-based conservation measures that are integrated into wider landscapes and seascapes.

Ambio has provided useful perspectives on how these protected area design issues could be addressed more effectively. Bengtsson et al. (2003) highlighted some of the limitations of protected areas, which covered just over $11 \%$ of the land at that time. Protected areas were considered too static when they need to be more dynamic. A dynamic landscape approach that mimics natural disturbance regimes could include, for example, successional lands that are recovering from over-exploitation; these resemble the territories managed by indigenous peoples such as the shifting cultivation practices described by Gadgil et al. (1993). Almost a decade later, Hanski (2011) presented detailed evidence that species can suffer from fragmented landscapes and protected areas are often too small to support viable populations, underlining the CBD target 11 point that connectivity of habitats is essential (also see Bengtsson et al. 2003). The importance of landscape 
connectivity is now in the conservation mainstream, with detailed guidelines prepared by an IUCN international team (Hilty et al. 2020).

The protected area design concepts of Hanski (2011) and Bengtsson et al. (2003) are now being addressed by governments under the CBD (Maxwell et al. 2020). They have adopted the concept of other effective area-based conservation measures (OECM), which are geographically defined areas other than protected areas that are governed and managed in ways that conserve biodiversity and ecosystem services and provide cultural, spiritual, and socio-economic benefits (SCBD 2018). They could include many landscapes owned or managed by indigenous peoples.

Today's environmental, social, economic, and political conditions require innovative responses that are appropriate to the emerging conditions. Climate change is a troubling reality, with floods, fires, heatwaves, and melting polar ice caps contributing new challenges to biodiversity, sustainable development, human health, and the effective management of protected areas. Many environmental problems are worsening, especially the loss of species (at a rate at least 1000 times the background rate-Pimm 2021), so conserving biodiversity in the coming decade will need to be well aware of how land management can support national and global efforts to address climate change and adapt to it. Bengtsson et al. (2021) have shown how some of the guiding concepts have been developed.

The responses to climate change and biodiversity loss provide the necessary ingredients to support a substantial increase in the amount of land, freshwater, and saltwater habitats receiving effective conservation management. It is timely to again follow E.O. Wilson, who has suggested that half of the land and freshwater habitats and at least a third of the coastal and marine habitats should be under biodiversity-oriented spatial planning and management regimes (Wilson 2016). This could include protected areas, restoration of degraded lands, other effective habitat management, lands managed by Indigenous peoples, nature-based solutions, urban protected areas, and other conservation-based habitat management as called for by all of the contributors to this Ambio issue.

\section{REFERENCES}

Bengtsson, J., P. Angelstam, T. Elmqvist, U. Emanuelsson, C. Folke, M. Ihse, F. Moberg, and M. Nyström. 2003. Reserves, resilience and dynamic landscapes. Ambio 32: 389-396. https://doi.org/10. 1579/0044-7447-32.6.389.

Bengtsson, J., P. Angelstam, T. Elmqvist, U. Emanuelsson, C. Folke, M. Ihse, F. Moberg, and M. Nyström. 2021. Reserves, resilience and dynamic landscapes 20 years later. 50th Anniversary Collection: Biodiversity conservation. Ambio 50. https://doi.org/10. 1007/s13280-020-01477-8.

CBD. 1992. The convention on biological diversity. Montreal: Secretariat of the Convention on Biological Diversity.

Doyle, C. 2015. Indigenous peoples, title to territory, rights and resources. New York: Routledge.

Gadgil, M., F. Berkes, and C. Folke. 1993. Indigenous knowledge for biodiversity conservation. Ambio 22: 151-156.

Gadgil, M., F. Berkes, and C. Folke. 2021. Indigenous knowledge: From local to global. 50th Anniversary Collection: Biodiversity conservation. Ambio 50. https://doi.org/10.1007/s13280-02001478-7.

Gilbert, J. 2016. Indigenous peoples' land rights under international law: From victims to actors. Leiden: Brill.

Hanski, I. 2011. Habitat loss, the dynamics of biodiversity, and a perspective on conservation. Ambio 40: 248-255. https://doi.org/ 10.1007/s13280-011-0147-3.

Hilty, J., G. Worboys, A. Keely, S. Woodley, B. Lauche, H. Locke, M. Carr, I. Pulsford, et al. 2020. Guidelines for conserving connectivity through ecological networks and corridors. Gland: International Union for Conservation of Nature.

Maxwell, S., V. Cazalis, N. Dudley, M. Hoffmann, A. Rodrigues, S. Stolton, P. Visconti, S. Woodley, N. Kingston, et al. 2020. Areabased conservation in the twenty-first century. Nature 586: 217-227.

Pimm, S. 2021. What is biodiversity conservation? 50th Anniversary Collection: Biodiversity conservation. Ambio. https://doi.org/10. 1007/s13280-020-01399-5.

Sayer, J., C. Margules, and J.A. McNeely. 2021. People and biodiversity in the 21 st century. 50th Anniversary Collection: Biodiversity conservation. Ambio 50. https://doi.org/10.1007/ s13280-020-01476-9.

SCBD. 2018. Protected areas and other effective area-based conservation measures. Montreal: Secretariat of the Convention on Biological Diversity.

Wilson, E.O. 1975. Sociobiology: The new synthesis. Cambridge: Harvard University Press.

Wilson, E.O. (ed.). 1988. Biodiversity. Washington: National Academy Press.

Wilson, E.O. 2016. Half-earth: Our planet's fight for survival. New York: Norton.

Publisher's Note Springer Nature remains neutral with regard to jurisdictional claims in published maps and institutional affiliations.

Jeffrey A. McNeely ( $\square)$

Address: Society for Conservation Biology Asia Section, Petchburi, Thailand.

e-mail: jeffmcneely2@gmail.com 


\section{Indigenous Knowledge for Biodiversity Conservation}

Indigenous peoples with a historical continuity of resourceuse practices often possess a broad knowledge base of the behavior of complex ecological systems in their own localities. This knowledge has accumulated through a long series of observations transmitted from generation to generation. Such "diachronic" observations can be of great value and complement the "synchronic" observations on which western science is based. Where indigenous peoples have depended, for long periods of time, on local environments for the provision of a variety of resources, they have developed a stake in conserving, and in some cases, enhancing, biodiversity. They are aware that biological diversity is a crucial factor in generating the ecological services and natural resources on which they depend. Some indigenous groups manipulate the local landscape to augment its heterogeneity, and some have been found to be motivated to restore biodiversity in degraded landscapes. Their practices for the conservation of biodiversity were grounded in a series of rules of thumb which are apparently arrived at through a trial and error process over a long historical time period. This implies that their knowledge base is indefinite and their implementation involves an intimate relationship with the belief system. Such knowledge is difficult for western science to understand. It is vital, however, that the value of the knowledge-practice-belief complex of indigenous peoples relating to conservation of biodiversity is fully recognized if ecosystems and biodiversity are to be managed sustainably. Conserving this knowledge would be most appropriately accomplished through promoting the community-based resource-management systems of indigenous peoples.

\section{INDIGENOUS AND MODERN KNOWLEDGE}

Knowledge is an outcome of model-making about the functioning of the natural world. All societies, pre-scientific and scientific strive to make sense of how the natural world behaves and to apply this knowledge to guide practices of manipulating the environment. Before the elaboration of the modern hypothetico-deductive method of systematically accumulating understanding of the functioning of the natural world, pre-scientific societies accumulated knowledge at a rather slow pace. Much of this knowledge was qualitative and based on observations on a rather restricted geographical scale. Within these bounds, reference to habitat preferences, life histories and behavior patterns of prey species such as birds, could be amazingly detailed $(1,2)$. Models of how the natural world functions as well as prescriptions on how to manipulate it are inevitably linked to any society's world view. However, in pre-scientific societies such models and prescriptions are much more closely integrated with moral and religous belief systems, so that knowledge, practice and beliefs co-evolve.

Modern scientific knowledge, with its accompanying world view of humans as being apart from and above the natural world has been extraordinarily successful in furthering human understanding and manipulation of simpler systems. However, neither this world view nor scientific knowledge have been particularly successful when confronted with complex ecological systems. These complex systems vary greatly on spatial and temporal scales rendering the generalizations that positivistic science has come up with of little value in furnishing practical prescriptions for sustainable resource use $(3,4)$. Science-based societies have tended to overuse and simplify such complex ecological systems, resulting in a whole series of problems of resource exhaustion and environmental degradation.

It is in this context that the knowledge of indigenous societies accumulated over historical time, is of significance. The view of humans as a part of the natural world and a belief system stressing respect for the rest of the natural world is of value for evolving sustainable relations with the natural-resource base (5).

Not all pre-scientific societies have necessarily lived harmoniously with the natural world, and not all indigenous peoples, outside industrial societies do so today (6). For example, some nomadic hunter-gatherers, who are not tied to any specific resource base and without well-defined territories, may gain little from prudent resource use. The same is true for agriculturists colonizing new territories with options of moving on to new localities as resources are exhausted. Rather, it is the more sedentary fishing, horticultural or subsistence agricultural societies with considerable dependence on hunting and gathering in their immediate neighborhoods that are most likely to have accumulated long series of historical observations of relevance to sustainable resource use and conservation of biodiversity. Self-regulatory mechanisms tend to evolve in such societies when they are faced with resource limitations. Among these mechanisms is a recognition and accumulation of knowledge about the important role that species play in generating ecological services and natural resources. As several major studies point out, indigenous knowledge, or traditional ecological knowledge, is of significance from a conservation perspective and an attribute of societies with continuity in resource use practices $(7,8)$.

Indigenous knowledge is herein defined as a cumulative body of knowledge and beliefs handed down through generations by cultural transmission about the relationship of living beings, (including humans) with one another and with their environment (9).

Many indigenous societies depended on a rather limited resource catchment of a few hundred square kilometers to provide them with a wide diversity of resources. This is not to say that they were isolated societies; many had ongoing trade and social relationships with more complex societies. However, the extent to which indigenous societies transformed local resources through manufacturing was limited, as was their ability to supplement locally available resources with imports. Thus, there were strong incentives for indigenous people to nurture and sustain diversity in their immediate environs (10). They may therefore be expected not only to conserve locally present natural biodiversity, but also to augment it by manipulating the landscape. Such manipulations could increase landscape patchiness, for instance by introducing various successional stages, thereby enhancing diversity in local resource catchments.

This paper examines local biodiversity conservation and enhancement activities of indigenous peoples, the knowledge base 


\section{Reserves, Resilience and Dynamic Landscapes}

In a world increasingly modified by human activities, the conservation of biodiversity is essential as insurance to maintain resilient ecosystems and ensure a sustainable flow of ecosystem goods and services to society. However, existing reserves and national parks are unlikely to incorporate the long-term and large-scale dynamics of ecosystems. Hence, conservation strategies have to actively incorporate the large areas of land that are managed for human use. For ecosystems to reorganize after large-scale natural and human-induced disturbances, spatial resilience in the form of ecological memory is a prerequisite. The ecological memory is composed of the species, interactions and structures that make ecosystem reorganization possible, and its components may be found within disturbed patches as well in the surrounding landscape. Present static reserves should be complemented with dynamic reserves, such as ecological fallows and dynamic successional reserves, that are part of ecosystem management mimicking natural disturbance regimes at the landscape level.

\section{INTRODUCTION}

The Convention on Biological Diversity commits the 177 signatory countries to conserve and sustainably use biological diversity. The long-term conservation of biodiversity requires an understanding of the processes that allow species to persist in natural as well as human-dominated ecosystems. During most of the 20th century, nature reserves and national parks have been a cornerstone in the preservation of species and natural areas. However, as more and more of the earth is modified by humans (1), the mismatches in scale between present nature reserves and the natural dynamics of ecosystems $(2,3)$ become more pronounced. This makes it even more difficult to achieve the goal of preserving biodiversity using reserves and national parks as the main tools.

Although reserves have been crucial for preserving species and habitats in the short term, with few exceptions they have not incorporated the long-term and large-scale dynamics of ecosystems as parts of dynamic landscapes (2-5). In this article, we argue that when the natural dynamics of communities and ecosystems are taken into account, a reconsideration is required of how reserves are designed and managed as parts of dynamic landscapes increasingly dominated by humans.

Reserves and national parks are geographically defined areas protected by the law, and in which human activities are restricted or prohibited (6). They are usually created with the intention to protect and preserve species and habitats, and are selected to maintain existing diversity and recreation values. Most reserves have been treated as static entities that should remain essentially the same and in the same place for centuries (7). Often, reserves are created to balance intensive land use in surrounding areas, and generally reserves have been placed on marginal lands ( 8 , 9 ). With this approach there is a high risk of ending up with small areas of reserves as islands in an intensively managed landscape. Also, the spatial and temporal scales of organism and ecosystem dynamics in intensively managed landscapes will be determined by human objectives, often disconnected from the scales of natural processes (10).

Since less than $3 \%$ of the earth's surface area $(6.4 \%$ of the land area) $(6,9)$ is protected, the traditional approach to nature reserves is unlikely to be sufficient for long-term biodiversity conservation. Neither will such a small protected area sustain the life-support systems and ecosystem services that humans depend upon. An alternative to the approach of static reserves is to recognize that humans are a part of and not apart from nature, which implies that conservation of biodiversity and preservation of ecosystem services is of concern for all land use (11, 12). Ecosystem management has been advanced as a tool to preserve biodiversity in reserves as well as managed landscapes (13-15).

Ecosystems are subject to natural and human-induced disturbances at various spatial and temporal scales $(5,16)$. Recent work has shown that humans tend to manage frequent and sometimes intermediately frequent disturbances, without perceiving the slow and rare ones (17). This is also the case in the present design of most nature reserves and parks. In the long term, it will be difficult to exclude large disturbances. Hence, an exclusive focus on static reserves as the main tool for biodiversity conservation will lead to failure of the very idea of nature reserves. To be useful, reserves should not be isolated and static, but be regarded as parts of dynamic landscapes. The long-term goal should be to create resilient landscapes of high biodiversity that make reorganization after disturbances possible in the future.

The importance of recognizing natural disturbance regimes in reserve design was emphasized already by Pickett and Thompson (3). They argued that reserves should be designed based on 'minimum dynamic area', defined as "the smallest area with a natural disturbance regime which maintains internal recolonization sources". However, for several reasons this criterion is difficult to apply in real situations. Firstly, in many areas of the world, such as Europe and the US Mid-West, the remaining patches of natural ecosystems are so small, scattered and surrounded by intensively managed land that minimum dynamic area within one reserve or reserve network is impossible to achieve. Secondly, recent work on natural disturbance regimes shows that large-scale rare events in ecosystems have been given too little attention (16). Hence, minimum dynamic areas depend on the time scale of interest. Thirdly, the projected global climatic changes make any reliance on internal recolonization questionable.

For the long-term sustainability of ecosystems and the services they generate, the preservation of biodiversity as insurance is often viewed as essential $(11,18)$. This means that a sustainable ecosystem - a system that remains functional-contains functional groups that each have a large number of substitutable insurance species that may seem to be unimportant for the present structure and function of the system (18-20). We term this network of species, their dynamic interactions between each other and the environment, and the combination of structures that make reorganization after disturbance possible; the "ecological memory" of the system $(21,22)$. One component of the ecological memory is the "biological legacies" discussed by, e.g. Turner et al. (23) and Franklin and MacMahon (24). The ecological memory is a key component of ecological resilience, i.e. the capacity of the system to absorb disturbances, reorganize, and maintain adaptive capacity $(25)$

Different areas of the world have different history and hence different amounts of ecological memory available. For example, Europe has a much longer history of intense human exploitation of its ecosystems than comparable areas in North America. In most European forests the amount of biological legacies is 


\title{
SYNOPSIS
}

\section{Habitat Loss, the Dynamics of Biodiversity, and a Perspective on Conservation}

\author{
Ilkka Hanski
}

Published online: 18 March 2011

A synopsis by the Crafoord Laureate in Biosciences 2011.

\section{INTRODUCTION}

Habitat loss has been, and still is, the greatest threat to biodiversity (Brooks et al. 2002; Hanski 2005; Groom et al. 2006). According to the Millennium Ecosystem Assessment (2005), more than half of several biomes, including the Mediterranean and temperate forests and tropical and sub-tropical dry broadleaf forests, had been converted by 1990; in Western Europe, only 2-3\% of original forests remain in natural or natural-like condition (WWF Report 2001). Zooming into more detailed classifications of habitat does not change the picture. As an example, a recent indepth assessment of changes in the quality and quantity of 368 habitat types in Finland (Raunio et al. 2008) classified the vast majority either as threatened (189 habitat types) or near threatened (105), while only 74 habitat types were considered to be of least concern. The conversion of natural habitats to agricultural land, pastures, plantations, built areas and infrastructure continues, propelled by increasing human population size and by accelerating demand for resources.

It is self-evident that populations and species will suffer when their habitat becomes degraded or is lost completely. Nonetheless, many issues concerning the response of biodiversity to habitat loss and fragmentation are less clear-cut or they are not widely appreciated. These issues include non-linearity in the ecological response of species to habitat loss and fragmentation at the landscape level, about which I have more to say in this article. The response of species to habitat loss and other environmental changes is typically not instantaneous, particularly not when we consider changes at large spatial scales. Habitat loss leaves large numbers of species to gradually decline and go extinct. If we are not aware of this "extinction debt" (Tilman et al. 1994) we are prone to underestimate the level of threat to biodiversity (Hanski and Ovaskainen 2002). Habitat loss often involves deteriorating habitat quality, either due to intentional changes in land use, such as the conversion of natural boreal forests to intensively managed forests in northern Europe, or due to unintentional damage, exemplified by increasing edge effects with decreasing area and increasing fragmentation of habitat. Hundreds of studies have examined the relative roles of habitat quality, habitat fragment area and connectivity (inverse of isolation) in influencing the occurrence of species in fragmented landscapes (reviewed by Fahrig 1997, 2003; Prugh et al. 2008). Unfortunately, much of this work is of limited value as it does not adequately recognize that the relative roles of habitat quality, fragment area and connectivity depend greatly on landscape structure and heterogeneity, and hence there cannot be a universal answer to the question "which is more important" (Hanski 2005).

Habitat loss and fragmentation have genetic and evolutionary consequences. I shall touch below the question about reduced viability of small and fragmented populations due to inbreeding and random fixation of deleterious mutations. Concerning the evolutionary dynamics, habitat loss and fragmentation are likely to alter many components of natural selection and hence lead to evolutionary change. A prime example is selection on dispersal: several costs and benefits of dispersal are affected by the spatial structure of populations and hence by the physical structure of 